\title{
Prof. Dr. Doğan Taner's Role in The Foundation Years of Hacettepe University Faculty of Medicine and His Perspective on the Medical Education
}

Ayşegül Fırat', [MD]

ORCID: 0000-0001-5105-0057
'Hacettepe University Faculty of Medicine, Department of Anatomy, Ankara, Turkey.

Corresponding Author: Ayşegül Fırat Hacettepe University Faculty of Medicine, Department of Anatomy, Ankara, Turkey. Phone: +90 3123052132

E-mail: aysfirat@hacettepe.edu.tr

https://doi.org/10.32552/2021.ActaMedica.587

Received: 18 April 2021, Accepted: 16 June 2021 Published online: 23 June 2021
When Hacettepe Medical Center became operational in 1957, it consisted of a children's hospital with 150 beds and adult hospital with 65 beds. Since 1961, with the expansion of the hospital, it was decided to establish a Faculty of Medicine and a Faculty of Health Sciences, and a Medical Education Committee was established under the chairmanship of Prof. Dr. İhsan Doğramacı. During the summer months of 1961, the committee examined the education systems of medical schools in our country and around the world, and documented the need for a new medical education [1]. While laying the foundation for a new medical education, it was decided to increase the capacity of the adult hospital. The construction of Hacettepe Medical School's Basic Sciences Department and interdisciplinary research labs were completed in 1965. In the process of creating training staff, 25 graduates who were carefully selected and graduated from other departments were sent to various universities in the United States for two to five years to obtain training in basic medical sciences. These doctors formed a core staff that educates in Pediatrics when they returned [1]. During the same period, other medical doctors abroad also applied for various positions in the faculty to evaluate this new and good opportunity. At that period, in our faculties, traditionally young doctors could not take on the responsibility of teaching because it was said that they lacked experience. In Hacettepe, the situation was different: After good references, a rigorous interview and careful screening, a young and qualified medical education team was established. Hacettepe Medical Center accepted its first students in the fall of 1964. The education committee which meets once a week in the following time has continued to develop by constantly discussing the strengths and weaknesses of training programs. The background of the students to be admitted to the faculty, full-time studies of faculties, integrated education system, curriculums, public health studies, students encountering patients from the first year, undergraduate internship, family medicine studies, multidisciplinary laboratories, research simulations, exam system, grades and basis of small discussion groups were always laid during this period. In order to enable 
the coordination among the departments, three main departments were designated under the Medical Faculty: Basic sciences, Clinical Sciences and Community Medicine. Each main department has its own chairman and they comprise the highest executive committee of the medical school. These main departments are divided into subdepartments headed by a professor. For example, Basic Sciences Unit included Anatomy, Physiology, Biochemistry, Pathology, Microbiology and Pharmacology departments $[1,2]$. In addition, in clinical education years, per-patient education was introduced and this system was soon recognized as Hacettepe education system in the national and international community [2].

Prof. Dr. Doğan Taner (1930-2021), after graduating from Istanbul University Cerrahpaşa School of Medicine in 1955, received his specialized training at New York Medical Center (the USA) and continued his post-career studies at London St. John's Hospital and West Hendon Hospital (England). He joined the Hacettepe family in these early years, planning to provide modern and highly qualified medical services in addition to research and high standards of health sciences and medical education. He held important administrative duties such as phase 1 Coordinator of the Faculty of Medicine (1965-1966, 1969-1971), Chief Coordinator of Medical Education (1971-1981), Head of the Department of Basic Medical Sciences (1973-1981, 1994-1997), Dean of Faculty of Health Sciences (1975-1981), Dean of the Faculty of Medicine (31.7.1981-2.9.1991) and Editor of Hacettepe Medical Journal (1983-1991). He is one of the founders of Hacettepe University Faculty of Medicine Department of Anatomy and maintained his position as the head of the department for many years. In addition to these duties in the university, he also worked as a member and consultant in many national and international higher education and medical education institutions.

As the dean of Hacettepe University Faculty of Medicine for the longest time (1981-1998), Prof. Dr. Doğan Taner shared his opinions and experiences about medical education in his various speeches and essays with his colleagues. According to our mentor, the traditional mission of medical faculty is to produce a biomedical knowledge accumulation at a high level and to raise good medical doctors; and he counts providing public health services as the third task. Our mentor cares about education, research, and public health services equally. He attached great importance to how these three functions should be carried out without disrupting the main task of medical education [3]. In the history of medical schools, education and research have always been prioritized and faculties have been isolated from society. In time, increasing social needs have caused the universities and especially medical faculties to revise their vision and missions in accordance with the needs of the society. Prof. Dr. Doğan Taner accordingly summarized the duties of Hacettepe University Medical Faculty and other medical faculties as such [3]:

1. To raise good doctors. For this purpose, a balance should be provided among the selection of qualified students and the physical conditions with the number of students.

2. The importance of research is obvious. Accordingly, it is necessary to find financial resources.

3. Preventive health services and ancillaries is the third basic task of the medical faculties. For some of the members, this is the vital task of medical faculties. Medical schools are capable of identifying and changing the needs and changes of society. However, this should not preclude the other two tasks. Research, education and public health services must be carried out together and evenly.

There are two types of postgraduate training programs in Turkey: clinical specialty training programs and master's and doctoral programs in basic sciences. These programs can be conducted at training hospitals and universities affiliated to the Ministry of Health in variable times. Also, some high specialty fields affiliated to the departments provide the opportunity of post-specialty training. Since 1987, the graduates have been given the right to specialize with a specialty exam done twice a year. With this exam, every graduate has the chance to specialize with the exam under equal conditions. In those years, half of the medical school graduates were specialists and the other half served as general practitioners. The foundation for the specialty training of family physician was laid during those years. The universities started to conduct the exams before the master and doctorate in basic sciences. During this period, health services in small villages was conducted at health centers affiliated to The 
Ministry of Health, whereas it was carried out at university and Ministry of Health hospitals and private hospitals in the cities. In these years, Prof. Dr. Doğan Taner served at many institutions related to medical education. In addition to the Association of Medical Education in Europe (1972-1994) and the Turkish Medical Education Institution (19841994), he served on boards such as the Association of Medical Deans in Europe executive committee (1990-1993) and guided medical education with his ideas. He held positions in councils that constantly emphasized the importance of organizing courses and meetings in determining the role and programs of the universities. He performed duties in the foundation and development of these systems such as the advisor of High Education Board (1997), member of Group for Raising Scientists of The Scientific And Technological Research Council Of Turkey (1991-1993). He emphasized that the development of medical education can be reached through the cooperation and coordination efforts of the Ministry of Health, the Turkish Medical Association, the Turkish Universities Council for Higher Education and the Higher Education Council with the universities [2]. He told about his efforts towards making decisions for the maintenance of continuing medical education with need-oriented training and certificate programs managing these practices especially by Turkish Medical Association. He drew attention to the fact that continuing medical education activities should be conducted in a planned and organized way in accordance with the needs of the society and the doctors and the doctors should keep up with the rapidly changing and advancing knowledge.

Medical faculties which need to take action with the mission of "health for everybody" should educate doctors planning the needs of not only today but future as well. Holding many administrative positions including deanship at Hacettepe University Faculty of Medicine for many years since its founding, Prof. Dr. Doğan Taner shaped the mission and vision of the medical faculty with these opinions. He always prioritised the qualified education of health professionals and the benefit of society in all the institutions he worked that shaped pre-graduation and post-graduation education.

As a medical student, I was very lucky to attend his anatomy lectures. He was one of the professors that is excited about research, teaching and integration of the basic sciences with the clinical practices. He had the experience and enthusiasm about planning the clinical anatomy lectures which would be the first among medical faculties. As a mentor he will be remembered with his emphasis on clinically applied anatomy lectures, giving importance to learning a foreign language and studying regularly.

\section{CONFLICT Of INTEREST}

The author has no conflict of interest with the submission.
[1] Dogramaci I. A New System of Medical Education in Turkey. J Med Educ. 1966; 41: 1063-1070.

[2] Taner D. Continuing Medical Education in Turkey. Postgrad Med J. 1993; 69(S2): S103-S105.
[3] Taner D. Responsibilities of Medical Schools and Society. Hacet Med J. 1983; 16(4): 147-149. 